\title{
GPS Zenith Total Delays and Precipitable Water in comparison with special meteorological observations in Verona (Italy) during MAP-SOP
}

\author{
Mauro Boccolari $\left({ }^{1}\right)$, Slobodan Fazlagic $\left({ }^{1}\right)$, Paolo Frontero $\left({ }^{2}\right)$, Luca Lombroso $\left({ }^{1}\right)$, \\ Sergio Pugnaghi $\left({ }^{1}\right)$, Renato Santangelo $\left({ }^{1}\right)$, Stefano Corradini $\left({ }^{1}\right)$ and Sergio Teggi $\left({ }^{3}\right)$ \\ $\left({ }^{1}\right)$ DIMA - Osservatorio Geofisico (OGMO), Università di Modena e Reggio Emilia, Italy \\ ${ }^{2}$ ) ARPAV Department of Verona Province, Verona, Italy \\ (3) DIMEC - Università di Modena e Reggio Emilia, Italy
}

\begin{abstract}
Continuous meteorological examination of the Pre-Alpine zones in Northern Italy (Po Valley) is important for determination of atmospheric water cycles connected with floods and rainfalls. During a special meteorological observing period (MAP-SOP), radiosounding and other measurements were made in the site of Verona (Italy). This paper deals with Zenith Total Delay (ZTD) and Precipitable Water (PW) comparisons obtained by GPS, radiosounding and other meteorological measurements. PW and ZTD from ground-based GPS data in comparison with classical techniques (e.g., WVR, radiosounding) from recent literature present an accurate tool for use in meteorology applications (e.g., assimilation in Numerical Weather Prediction (NWP) models on short-range precipitation forecasts). Comparison of such ZTD for MAP-SOP showed a standard deviation of $16.1 \mathrm{~mm}$ and PW comparison showed a standard deviation of $2.7 \mathrm{~mm}$, confirming the accuracy of GPS measurements for meteorology applications. In addition, PW data and its time variation are also matched with time series of meteorological situations. Those results indicate that changes in PW values could be connected to changes in air masses, i.e. to passages of both cold and warm fronts. There is also a correlation between precipitation, forthcoming increase and the following decrease of PW. A good agreement between oscillation of PW and precipitation and strong cyclonic activities is found.
\end{abstract}

Key words precipitable water - zenith total delay radiosounding - GPS

\section{Introduction}

During MAP-SOP (Bougeault at al., 2001) field experiments (Mesoscale Alpine Program/ Special Observing Period, September-November

Mailing address: Dr. Mauro Boccolari, Dipartimento di Ingegneria dei Materiali e dell'Ambiente (Osservatorio Geofisico), Università di Modena e Reggio Emilia, Via Vignolese 905, 41100 Modena, Italy; e-mail: mauro.boccolari@unimo.it
1999), the special observation station in Verona was set up mainly for inflow probing, and upstream-measurements related to gap-flow studies in connection with neighbouring Alpine valleys (the flow over the upstream side of the Adige Valley should have an important role in precipitation triggering processes, both convective and stratiform). The enhancement of precipitation and related floods during warm and moist south-westerly flow in the Pre-Alpine zones in Northern Italy is another process that needs more explanation, both for improving parameterization in NWP and improving the short-range forecasts. Meteorological radiosondes 
are a fairly accurate but temporally limited classic source of humidity observations. To overcome the time discontinuity of vertical humidity measurements, a GPS receiver could be used as a continuous source of atmospheric measurements (Businger et al., 1996).

Atmospheric refraction has a strong influence on GPS radio signals. The ionosphere disturbance on GPS electromagnetic waves is resolved in a satisfactory manner, thus the main task is to estimate better the neutral atmosphere impact. Signals are delayed in the neutral atmosphere because of the refraction, which is a function of temperature, pressure and water content. Satellites travel under different elevation angles, but taking a convenient mapping function, the zenith direction is commonly considered. All components of the troposphere contribute to such zenith delay, but it is convenient to study its hydrostatic and wet terms separately. The induced dipole moment of the atmosphere is associated with the Zenith Hydrostatic Delay (ZHD). Zenith Wet Delay (ZWD, non-hydrostatic) is mainly due to the permanent dipole moment of water vapor, which is highly variable in space and time: the ZWD is fully attributed with the content of water vapor along the signal path.

GPS data may serve for the estimation of integrated water vapor in the atmosphere (Bevis et al., 1992), using their Zenith Total Delay (ZTD). If the ZHD component (after being derived from a surface pressure modelling) is subtracted from ZTD, it leaves the ZWD, which is associated with the water vapor profile.

In the framework of the MAP/SOP campaign, the Geophysical Observatory of Modena University (OGMO) performed a consistent number of radiosounding (98) in Verona (Italy), on a weather forecast bases, issued by the MAP operation centre declaring the IOP (Intensive Observation Period). During the IOP, balloons were launched at six hour intervals or, in case of the extreme events, every three hours, looking for situations with the highest probability of intensive atmospheric processes (fronts, heavy precipitation, Foehn conditions, etc.). The limiting fact of radiosounding, having a variable vertical extent of measurements, was considered in this work. Surface meteorological data were also permanently recorded at the site.
The principal aim of this work was to compare radiosounding-based ZTD and PW (precipitable water) with delays and PW obtained from GPS analyses. The permanent GPS station in Padua (IGS network, located at $70 \mathrm{~km}$ distance from the Verona radiosounding site) was used for the comparison. Other authors have already presented comparisons of PW between GPS data and different measurement techniques: $e . g$., with WVR (Duan et al., 1996) and (Emardson et al., 1998), radiosounding and NWP modelling (Borbas, 1998) and (Vedel et al., 2001), lidars (Bock and Doerflinger, 2001), sun photometer (Pugnaghi et al., 2002).

The second aim of the work was to examine variations in PW estimates obtained from GPS with respect to the occurrence of significant meteorological events, followed in detail during MAP-SOP, in order to determine possible regularities in meteorological perspective.

\section{Zenith Total Delay comparison (radiosounding, GPS)}

\subsection{Zenith Total Delay from radiosounding}

Zenith Total Delay $(\mathrm{mm})$ is commonly expressed as

$$
\begin{gathered}
\mathrm{ZTD}=\int_{\text {ground }}^{\mathrm{TOA}} N(z) d z= \\
=\int_{\text {ground }}^{\mathrm{TOA}} N_{\text {dry }}(z) d z+\int_{\text {ground }}^{\mathrm{TOA}} N_{\text {wet }}(z) d z
\end{gathered}
$$

where $N, N_{\text {dry }}, N_{\text {wet }}$, are the total, dry and wet refractivity, $z$ is the geometric height. Refractivity can be expressed as (Thayer, 1974)

$$
N=N_{\text {dry }}+N_{\text {wet }}=k_{1} \frac{p_{d}}{T}+\left(k_{2} \frac{e}{T}+k_{3} \frac{e}{T^{2}}\right)
$$

where $p_{d}(\mathrm{hPa})$ is the partial pressure of dry air, $e$ $(\mathrm{hPa})$ is the partial pressure of water vapor, $T$ $(\mathrm{K})$ is the temperature, $k_{1}, k_{2}, k_{3}$ are empirical constants. In such work, constants derived by Bevis (Bevis et al., 1994) were used: $k_{1}=77.6$ 
$\mathrm{K} / \mathrm{hPa}, k_{2}=70.4, \mathrm{~K} / \mathrm{hPa}, k_{3}=3.73910^{5} \mathrm{~K}^{2} / \mathrm{hPa}$. Bevis constants were chosen because they are considered more suitable for deriving delays from meteorological data.

Using the previous equation, ZTD can be expressed in terms of pressure $d p$ as a sum of an hydrostatic part ZHD and a non-hydrostatic part ZNHD

$$
\begin{gathered}
\mathrm{ZTD}=\mathrm{ZHD}+\mathrm{ZNHD}=\int_{\text {TOA }}^{\text {ground }} k_{1} \frac{R_{d}}{g} d p+ \\
\int_{\text {TOA }}^{\text {ground }} \frac{q R_{d}}{g \varepsilon}\left[\left(k_{2}-k_{1} \varepsilon\right)+\frac{k_{3}}{T}\right] d p
\end{gathered}
$$

where $q$ is the specific humidity, $R_{d}$ is the specific constant of dry air, $g$ is the gravitational constant, $T$ is the temperature and $\varepsilon$ is the ratio of the water vapor constant to that of dry air. TOA stands for Top Of Atmosphere.

It should be noted that in literature, ZNHD is often referred as a wet delay.

Solving the integral for ZHD we obtain that it depends by only the surface pressure $p_{s}$

$$
\mathrm{ZHD}=k_{1} \frac{R_{d} p_{s}}{g}
$$

if the barometric pressure is known to $1 \mathrm{hPa}, \mathrm{ZHD}$ can be estimated with an accuracy of $2.3 \mathrm{~mm}$. The accuracy of barometric sondes used for radiosounding was $1 \mathrm{hPa}$.

Specific humidity in eq. (2.3) was calculated from the relative humidity (accuracy was the 3\%), measured by radiosounding device, using the Goff and Gratch formula (WMO, 1975).

In the case of the calculus based on radiosounding data, the integration was done from the ground surface to the upper end of the radiosounding.

\subsection{Zenith Total Delay modelling (from Saastamoinen formula)}

Zenith Total Delay may be calculated using a tropospheric delay model. For that purpose, we applied the well known Saastamoinen model (Saastamoinen, 1972) (neglecting the latitude and the station height effects)

$\mathrm{ZTD}_{\text {Saas }}=Z \mathrm{ZHD}_{\text {Saas }}+\mathrm{ZNHD}_{\text {Saas }}=0.002277 p_{s}+$

$$
+0.002277\left(0.005+\frac{1255}{T_{s}}\right) e_{s}
$$

where, again, ZHD (m) is the Zenith Hydrostatic Delay, ZNHD (m) is the Zenith Non Hydrostatic Delay, $p_{s}$ is the surface air pressure $(\mathrm{hPa}), T_{s}(\mathrm{~K})$ is the surface temperature, $e_{s}(\mathrm{hPa})$ is the surface water vapor pressure. It is evident that ZHD is the same as that in eq. (2.4).

\subsection{Vertical correction of radiosounding Zenith Total Delay}

Obviously, ZTD calculated by integration (eq. (2.1) for many low-reaching radiosoundings are underestimated. Maximum heights reached by balloons of radiosounding during the Verona field campaign varied from $2996 \mathrm{~m}$ to $19648 \mathrm{~m}$. A solution could be to take into consideration only radiosounding reaching a «chosen» height, but it would involve a very small data set for further analysis.

To use all radiosounding measurements for calculation of ZTD, a necessary correction for the uncovered part extent of the troposphere is made. For that purpose, we used Saastamoinen hydrostatic modelling based on surface meteorological data (eq. (2.5))

Looking for ways to overcome the «underestimated» $\mathrm{ZTD}_{\mathrm{RS}}$, we have already tried two equivalent methods for a vertical correction (Boccolari et al., 2001).

In this work, the applied method is: Zenith Non Hydrostatic Delay from radiosounding (second term of right hand of eq. (2.3), in which integration limits are the ground and the top of radiosounding) is corrected with ZNHD from the Saastamoinen formula for the upper part of atmosphere not covered by radiosounding $\left(\mathrm{ZNHD}_{\text {Saas (upper }}\right)$, applying Saastamoinen ZHD for the whole range 
(eq. (2.5))

$\mathrm{ZTD}_{C}=\mathrm{ZNHD}_{\mathrm{RS}}+\mathrm{ZNHD}_{\text {Saas(upper) }}+\mathrm{ZHD}_{\text {Saas }}$.

Hereafter, we take $\mathrm{ZTD}_{C}$ as «corrected».

\subsection{Zenith Total Delay from GPS data elaboration}

Due to large local radio interference with the GPS signal at Verona radiosounding site, GPSZTD were retrieved for the GPS permanent site in Padua (Italy), which belongs to IGS Network, as the nearest one to the Verona; the distance of approximately $70 \mathrm{~km}$, inside the range of baselines used by other authors, e.g., $50 \mathrm{~km}$ (Vedel et al., 2001); $100 \mathrm{~km}$ (Emardson et al., 1998).

From the Crustal Dynamics Data Information System Archive (CDDISA) at the NASA Goddard Space Flight Center, we retrieved the ZTD (combination of tropospheric estimates from all analysis centres by the GeoForschungsZentrum of Potsdam) with a sampling rate of $2 \mathrm{~h}$. Owing to the lack of GPS measurements in Padua for some days, the comparison set was reduced from 98 to 76 cases.

The difference between orthometric heights of Verona and Padua sites was $27.6 \mathrm{~m}\left(\mathrm{Z}_{\mathrm{pdova}}=\right.$ $\left.=39.4 \mathrm{~m} ; Z_{\text {verona }}=67.0 \mathrm{~m}\right)$. Such vertical offset corresponds roughly to a difference of $3.5 \mathrm{hPa}$, that is about $8 \mathrm{~mm}$ of difference for the ZHD. Considering that both stations belong to the mainly homogeneous meteorological field (Po Valley) and $95 \%$ of water vapor lies below $5 \mathrm{~km}$, the ZTD wet component difference should not be too significant $(1-0.5 \mathrm{~mm})$.

\subsection{Comparison of ZTD from GPS and (corrected) radiosounding}

Bias and standard deviation of ZTD between corrected radiosounding $\left(\mathrm{ZTD}_{C}\right)$ and Zenith Total

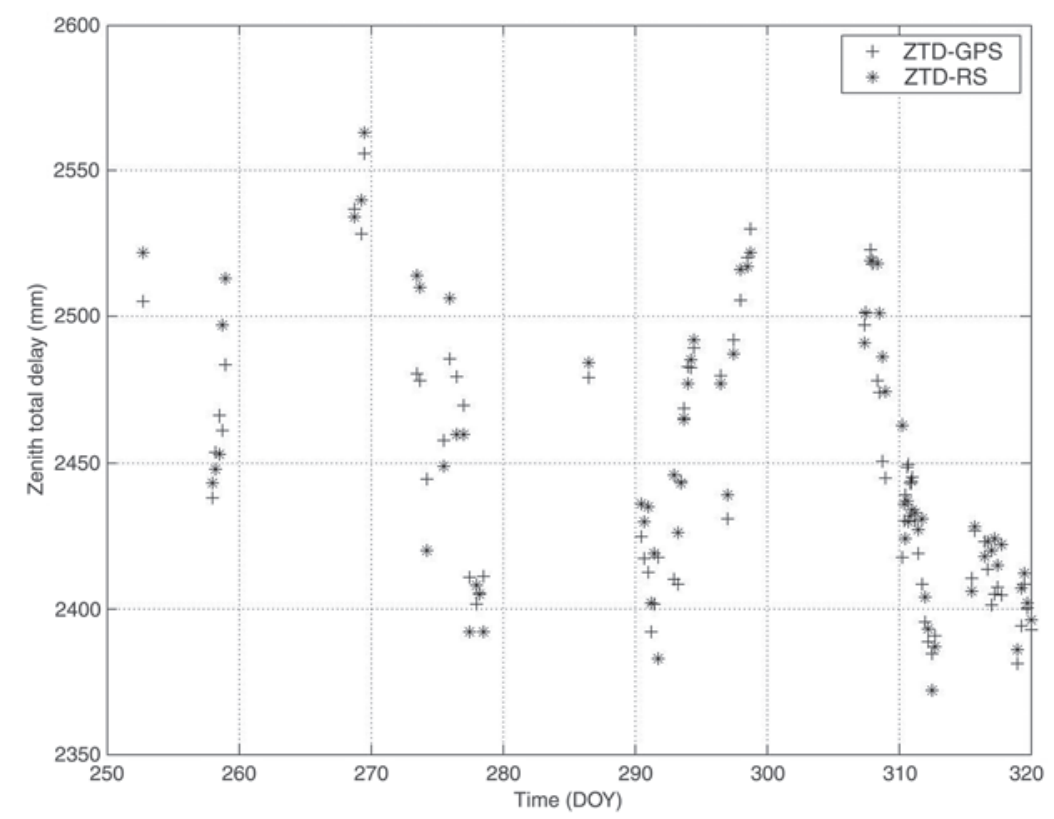

Fig. 1. ZTD by GPS for Padua and ZTD by radiosounding for Verona ( $\mathrm{mm}$ ) versus time for MAP-SOP period (DOY 250-320, 07 September - 16 November, 1999). 
Delay from GPS $\left(\mathrm{ZTD}_{\mathrm{GPS}}\right)$, without considering the vertical shift between the two sites, are

$$
\left\langle\mathrm{ZTD}_{\mathrm{GPS}}-\mathrm{ZTD}_{\mathrm{C}}\right\rangle=-5.1 \pm 16.1 \mathrm{~mm} \text {. }
$$

A recent comparison between ZTD-GPS and radiosounding-ZTD made by Vedel et al. (2001) gives the average offsets of $6.0 \mathrm{~mm} \pm 11.7 \mathrm{~mm}$ (see fig. 1).

\section{Precipitable Water (PW) comparison}

\subsection{PW from GPS}

Precipitable Water (denoted with $\mathrm{PW}_{\mathrm{GPS}}$ ) $(\mathrm{mm})$ estimate from GPS data is based on ZWD which is nearly linearly proportional to PW (mm). According to Bevis et al. (1994)

$$
\mathrm{PW}_{\mathrm{GPS}}=\mathrm{ZWD}_{\mathrm{GPS}} \cdot \Pi\left(T_{m}\right)
$$

where $\Pi\left(T_{m}\right)$ is a constant depending on the mean atmospheric temperature $T_{m}$. The value of 0.15 , usually accepted, was taken.

ZWD is obtained by subtracting ZHD (i.e. obtained with Saastamoinen formula) from the ZTD.

\section{2. $P W$ from radiosounding}

Precipitable Water (denoted with $\left.\mathrm{PW}_{\mathrm{RS}}\right)(\mathrm{mm})$ is calculated as a sum of the two terms $\left(\mathrm{PW}_{\text {lower }}+\right.$ $\left.+\mathrm{PW}_{\text {upper }}\right)$. The first term $\left(\mathrm{PW}_{\text {lower }}\right)$ is ZWD integrating of $N_{\text {wet }}^{\text {uppeq. }}$ (eq. (2.2)) from radiosounding data multiplied for the constant $\Pi\left(T_{m}\right)$, that is calculated with the following relation (Askne and Nordius, 1987):

$$
\Pi\left(T_{m}\right)=\frac{10^{6}}{\rho_{v} R_{v}\left(\frac{k_{3}}{T_{m}}+k_{2}-\varepsilon \cdot k_{1}\right)}
$$

where the mean atmospheric temperature $T_{m}$ is given by (Davis et al., 1985)

$$
T_{m}=\frac{\int\left(\frac{e}{T}\right) d z}{\int\left(\frac{e}{T^{2}}\right) d z} .
$$

Table I. Rms (mm) between PW by GPS and PW by radiosounding reported by other authors.

\begin{tabular}{lc}
\hline \hline \multicolumn{1}{c}{ Author(s) } & $\mathrm{Rms}(\mathrm{mm})$ \\
\hline Borbas (1998) & $2.3-2.6$ \\
Tregoning et al. (1998) & 1.5 \\
Emardson et al. $(1998)$ & $1.8-2.6$ \\
Baker et al. (2001) & $1.2-1.7$ \\
\hline
\end{tabular}

The second term $\left(\mathrm{PW}_{\text {upper }}\right)$ takes into account the upper part of atmosphere not covered by radiosounding. It is calculated from $\mathrm{ZNHD}_{\mathrm{S}}$ (eq. (2.3)) multiplied for the constant ${ }^{\text {Saasper }}$ calculated using eq. (3.2) for that upper layer. In conclusion

$$
\mathrm{PW}_{\mathrm{RS}}=\mathrm{ZWD}_{\mathrm{RS}} \Pi_{\text {lower }}+\mathrm{ZNHD}_{\text {Saas(upper) }} \Pi_{\text {upper }} \text {. }
$$

\subsection{PW comparison}

The bias and standard deviation of PW calculated from radiosounding and GPS (not considering the vertical offset between the two site) is

$$
\left\langle\mathrm{PW}_{\mathrm{GPS}}-\mathrm{PW}_{\mathrm{RS}}\right\rangle=-1.6 \pm 2.7 \mathrm{~mm} .
$$

The value of $2.7 \mathrm{~mm}$ is at the level of the rms indicated by other authors (see table I).

\section{GPS PW variation in comparison with observed meteorological data}

Surface meteorological data during MAP-SOP were recorded continuously (sampling rate of 10 $\mathrm{min}$ ) at the experimental (also radiosounding) site at Verona. As already seen in relation (3.5), the standard deviation of $\mathrm{PW}_{\mathrm{GPS}}$ and $\mathrm{PW}_{\mathrm{RS}}$ difference indicated the possibility to proceed with the comparison of continuous GPS PW and surface meteorological data.

Data on precipitation, atmospheric pressure, wind velocity, relative humidity and air temperature are used for the comparison with PW data. In order to express clearly the behaviour of PW we introduce here a symbol of the change of $\mathrm{PW}$, curve derivative coefficient (we call it briefly 


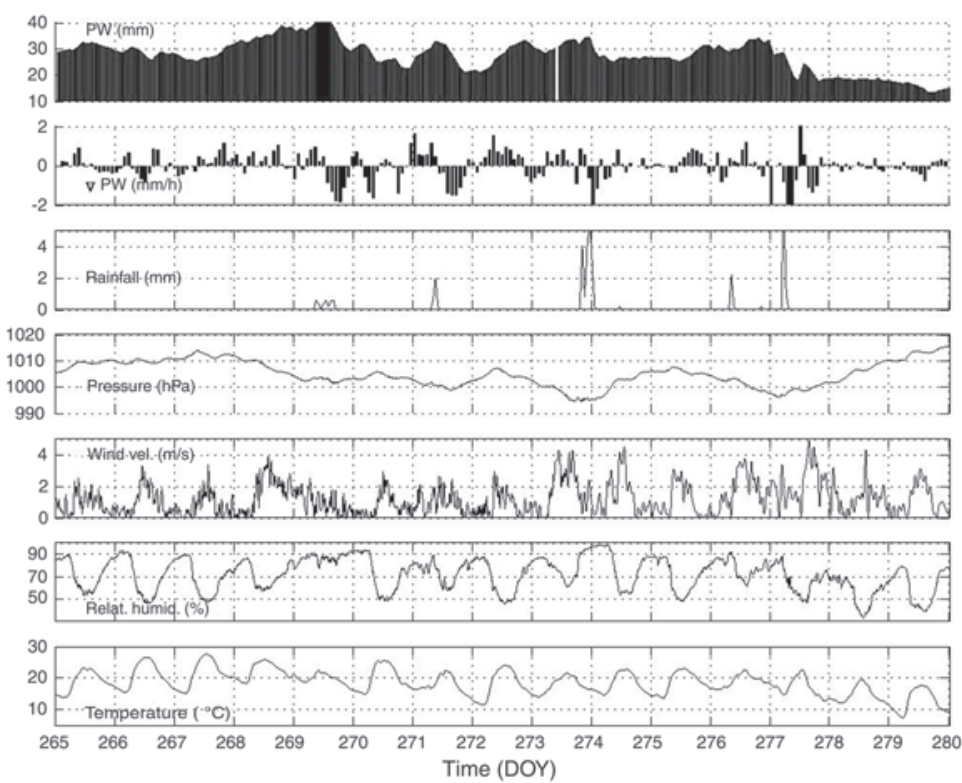

Fig. 2. Precipitable Water (PW, $\mathrm{mm})$ and $\mathrm{PW}$ curve derivative coefficient sign $(\nabla \mathrm{PW}, \mathrm{mm} / \mathrm{h})$ for Padua; barometric pressure $(\mathrm{hPa})$; wind velocity $(\mathrm{m} / \mathrm{s})$; relative humidity $(\%)$ and air temperature at $2 \mathrm{~m}\left({ }^{\circ} \mathrm{C}\right)$ for Verona versus time for period of DOY 265-280, 22 September - 07 October, 1999.

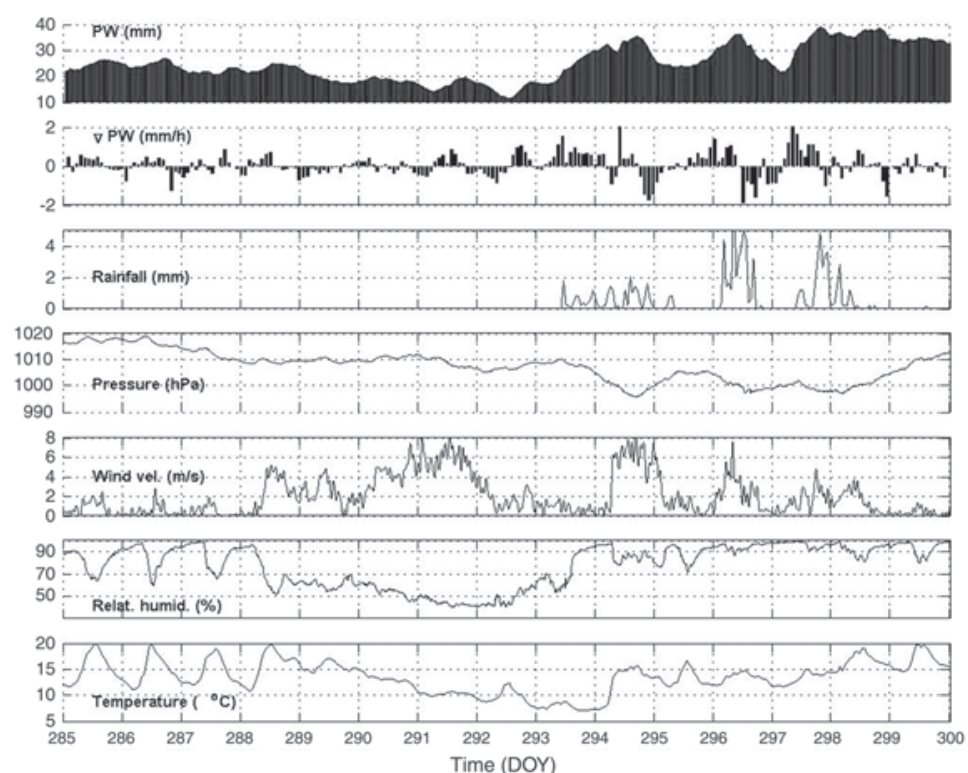

Fig. 3. Precipitable Water $(\mathrm{PW}, \mathrm{mm})$ and $\mathrm{PW}$ curve derivative coefficient sign $(\nabla \mathrm{PW}, \mathrm{mm} / \mathrm{h})$ for Padua; barometric pressure $(\mathrm{hPa})$; wind velocity $(\mathrm{m} / \mathrm{s})$; relative humidity $(\%)$ and air temperature at $2 \mathrm{~m}\left({ }^{\circ} \mathrm{C}\right)$ for Verona versus time for period of DOY 285-300, 12 October - 27 October, 1999. 


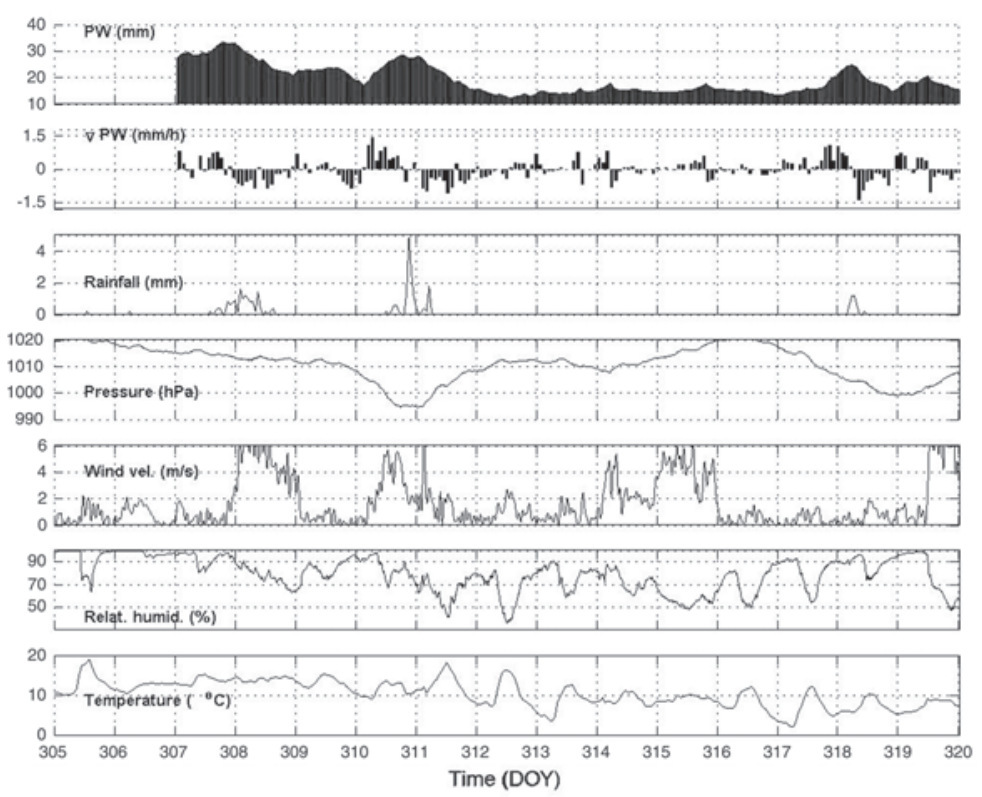

Fig. 4. Precipitable Water $(\mathrm{PW}, \mathrm{mm})$ and $\mathrm{PW}$ curve derivative coefficient sign $(\nabla \mathrm{PW}, \mathrm{mm} / \mathrm{h})$ for Padua; barometric pressure $(\mathrm{hPa})$; wind velocity $(\mathrm{m} / \mathrm{s})$; relative humidity $(\%)$ and air temperature at $2 \mathrm{~m}\left({ }^{\circ} \mathrm{C}\right)$ for Verona versus time for period of DOY 305-320, 01 November - 16 November, 1999.

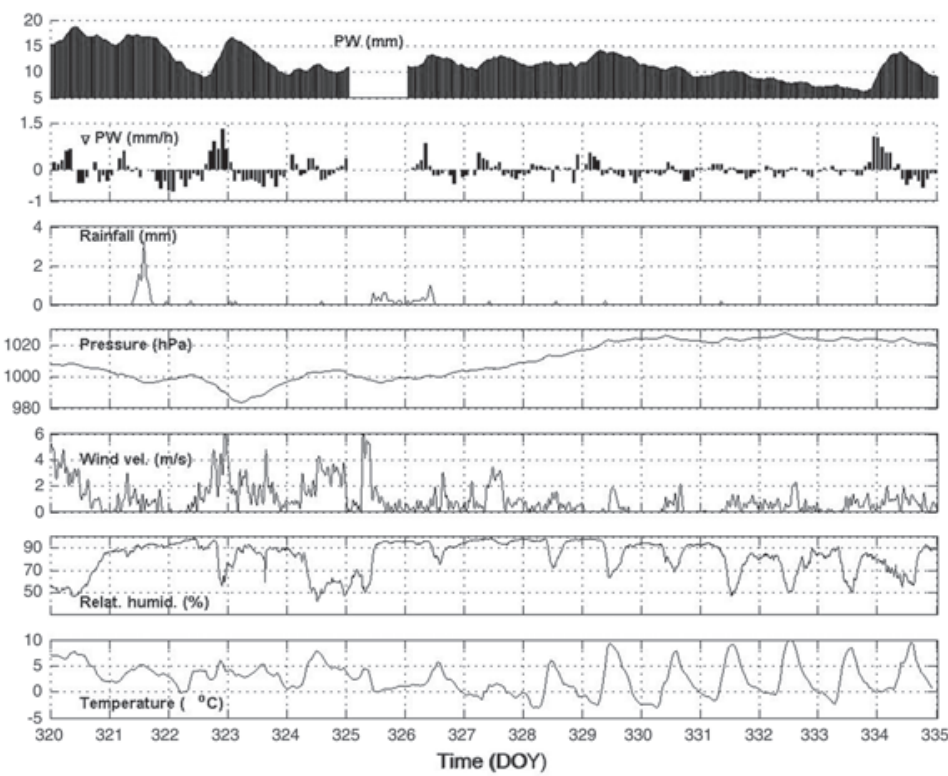

Fig. 5. Precipitable Water $(\mathrm{PW}, \mathrm{mm})$ and $\mathrm{PW}$ curve derivative coefficient $\operatorname{sign}(\nabla \mathrm{PW}, \mathrm{mm} / \mathrm{h})$ for Padua; barometric pressure $(\mathrm{hPa})$; wind velocity $(\mathrm{m} / \mathrm{s})$; relative humidity $(\%)$ and air temperature at $2 \mathrm{~m}\left({ }^{\circ} \mathrm{C}\right)$ for Verona versus time for period of DOY 320-335, 16 November - 01 December, 1999. 
gradient $\nabla \mathrm{PW}, \mathrm{mm} / \mathrm{h})$. Some more intense cases of $\nabla \mathrm{PW}$ are reported in order to indicate a possible tool for valorisation of ongoing numerical weather forecasts.

Figures 2 to 5 compare PW (first graph from the top) and PW gradient $\nabla \mathrm{PW}$ (second graph from the top) with the meteorological parameters. To have the temporal resolution presented in a more convenient manner, the entire MAP-SOP period is divided into four suitable time segments (DOY 265-280, DOY 285-300, DOY 305-320, DOY 320-335).

Generally, several indications are common to all four time segments. Changes in PW values could be related to atmospheric processes or to the state of air masses, i.e. to passages of both cold and warm fronts over the GPS observing site. Also, precipitation cases are usually accompanied by forthcoming increase and subsequent decrease of PW. Here we indicate some typical meteorological situations where GPS determined PW are confirming the fact to change together with strong weather changes.

In fig. 2 the intensive increase in PW which occurred in DOY 268 and 269 (25/26 September) could be followed. It corresponds to the southerly flow in both upper and low levels over the Northern Italy, strengthened even with the anticyclonic circulation over Central Mediterranean area. After the passage of the cold front and precipitation on 26.09 (third graph from the top), a heavy negative gradient of $\nabla \mathrm{PW}$ is noted (the second graph from the top). Also, other precipitation occurrences in that period were followed with the negative gradient of $\nabla \mathrm{PW}$ (DOY 271, 274, 277), all related to passages of disturbances, indicated with relative minimum of atmospheric pressure (fourth graph from the top).

In fig. 3 the PW minimum showed during DOY 292 (19 October) coupled with negative VPW. A no precipitation situation corresponds to the specific synoptic event with two airflow components - polar dry air circulation in upper level and easterly flow of cold and dry air in low level (indicated with increased wind velocities in fifth graph and decrease in relative humidity - sixth graph from the top). In the MAP-SOP documents that situation is described in details as IOP n. 8 . For the period of two consecutive days (DOY 294, 295) when the low precipitation episode was not immediately accompanied by a PW decrease, but at the end of the period, we explain by the constant influence of a strong elevated depression over the area. Later, 23rd and 25th October (DOY 296 and 298) show intensive oscillation between positive and negative $\nabla \mathrm{PW}$ after the significant precipitation cases, both connected with strong cyclonic activities (passages of warm fronts). Again, a relative maximum of PW values (DOY 299) is reported in the situation of strong southern circulation in the upper level.

In fig. 4 two significant episodes are distinguished. The first, between 4th and 5th November (DOY 308, 309) where weak precipitation was followed with the durable negative $\nabla \mathrm{PW}$, caused by the influence of two components - cut off closed in the Gulf of Genoa and easterly flow from Adriatic in surface anticyclonic circulation. The second, opposite case episode (DOY 311) demonstrates a PW decrease after the heavy precipitation brought by the formation of classical deep cyclonic circulation in the Gulf of Genoa and a rapid passage of the cold front. A long constant period of low PW values and absence of significant signs of $\nabla \mathrm{PW}$ is related to the domination of high pressure field (DOY 312317 ), again broken by the depression with precipitation in DOY 318.

In fig. 5 the episode with a strong decrease of PW after precipitation (DOY 321) should be distinguished. Immediately, it follows the next decrease of $\mathrm{PW}$ without precipitation, connected to the passage of the deep depression caused by the circulation of polar air mass. Low PW values in the high pressure field are interrupted at the end of the period (DOY 334) when easterly flow of the Adriatic wet air occurred caused by the strengthening of the Balcanic anticyclone.

To obtain a better correlation between GPS detected precipitable water and meteorological events, it would probably be necessary to introduce the elaboration of slant water vapor contribution along the different lines of sight GPS receiver-satellites (de Haan et al., 2002).

\section{Conclusions}

Using the MAP-SOP data set in comparison with GPS observations, we have confirmed that 
the limitation of the vertical extension of the radiosounding measurements for ZTD estimates could be resolved by adding a term from a tropospheric model (Saastamoinen). It is also confirmed that for meteorological applications, it is useful to estimate PW by GPS elaboration instead of from radiosounding, that occur as spatially and temporally limited.

Comparing ZTD from (corrected) radiosounding with ZTD from nearby GPS station data the standard deviation error of $16 \mathrm{~mm}$ is found, which is a reasonable value to be used in the numerical modelling.

Comparison of radiosounding PW estimates with GPS PW estimates shows standard deviation of $2.7 \mathrm{~mm}$. The bias (considering the vertical shift between two sites) is at the sub-millimetre scale. That standard deviation and bias correspond to the recent results of other authors (table I). As a consequence, precise GPS data may be used as an adequate source of integrated vertical humidity field for numerical weather modelling.

Surface meteorological analysis data during MAP-SOP are used for the comparison with GPS PW variations. Several indications are detected. Changes in PW values could be generally related to atmospheric processes, i.e. to passages of both cold and warm fronts over the GPS observing site. There is also a strong correlation between precipitation, forthcoming increase and the following decrease of PW. Some intensive oscillations between positive and negative PW variations come after the significant precipitation cases connected to strong cyclonic activities.

\section{Acknowledgements}

Authors express their gratitude to Crustal Dynamics Data Information System Archive (CDDISA) at the NASA Goddard Space Flight Center, GeoForschungsZentrum of Potsdam (GFZ) and MAP Data Centre ETH - Zürich for the data used in this work.

\section{REFERENCES}

ASKNE, J. and H. NORDIUS (1987): Estimation of tropospheric delay for microwaves from surface weather data, Radio Sci., 22, 379-386.
BAKer, H.C., A.H. Dodson, N.T. PEnNA, M. HigGins and D. OFFILER (2001): Ground-based GPS water vapour estimation: potential for meteorogical forecasting, J. Atmos. Sol. Terr. Phys., 63, 1305-1314.

Bevis, M., S. Businger, R. HERring, C. Rocken, R.A. ANTHES and H.R.WARE (1992): GPS meteorology: remote sensing of atmospheric water vapor using the Global Positioning System, J. Geophys. Res., 97, 15,78715,801 .

Bevis, M., S. Businger, S. Chiswell, R. Herring, R.A. ANTHES, C. ROCKEN and H.R. WARE (1994): GPS meteorology: mapping zenith wet delays onto precipitable water, J. Appl. Meteorol., 33, 379-386.

BoCCOLARI, M., S. FAZLAGIĆ, L. LOMBROSO, P. FRONTERO, S. Pugnaghi, R. Santangelo, S. Corradini and S. TEGGI (2001): Precipitable water estimation in comparison between Zenith Total Delays (ZTD) by radiosounding data and by GPS Data, MAP Newsletter n. $15,218-221$.

Bock, O. and E. DoERflinger (2001): Atmospheric modelling in GPS data analysis for high accuracy positioning, Phys. Chem. Earth (A), 26 (6-8), 373-383.

BORBAS, E. (1998): Derivation of precipitable water from GPS data: an application to meteorology, Phys. Chem. Earth, 23 (1), 87-90.

Bougeault, P., P. Binder, A. Buzzi, R. Dirks, R. Houze, J. Kuettner, R.B. SMith, R. STEInACKer and H. VOLKERT (2001): The MAP special observing period, Bull. Am. Meteorol. Soc., 82 (3), 637-650.

Businger, S., S.R. Chiswell, M. Bevis, J. Duan, R. A. Anthes, C. Rocken, R.H. WARE, M. Exner, T. VANHOVER and F.S. SOLHEIN (1996): The promise of GPS in atmospheric monitoring, Bull. Am. Meteorol. Soc., 77 (1), 5-18.

DAVIS, J.L., T.A. HERRING, I.I. SHAPIRO, A.E. Rogers and G. ELGERED (1985): Geodesy by radiointerferometry: effects of atmospheric modelling errors on estimates of baseline length, Radio Sci., 20, 1593-1607.

De Hann, S., H. VAN DER MAREL and S. BARLAG (2002): Comparison of GPS slant delay measurements to a numerical model: case study of a cold front passage, Phys. Chem. Earth, 27, 317-322.

Duan, J., M. Bevis, P. FANG, Y. Bock, S. Chiswell, S. Businger, C. Rocken, F. SOlHeim, T. VAN Hove, R. WARE, S. MCCLUSKY, T.A. HERring and R.W. KING (1996): GPS meteorology: direct estimation of the absolute value of precipitable water, J. Appl. Meteorol., 35, $830-838$.

EMARDSON, T.R., G. ELGERED and J.M. JOHANSSON (1998): Three months of continuous monitoring of atmospheric water vapor with a network of Global Positioning System receivers, J. Geophys. Res., 103 (D2), 1807-1820.

Pugnaghi, S., M. Boccolari, S. FAZlagić, R. PaCione, R. Santangelo, H. Vedel and F. Vespe (2002): Comparison of independent integrated water vapour estimates from GPS and sun photometer measurements and a meteorological model, Phys. Chem. Earth, 27, 355-362.

SAASTAMOINEN, J. (1972): Atmospheric correction for the troposphere and stratosphere in radio ranging of satellites, in The Use of Artificial Satellites for Geodesy, 
Geophys. Monogr. Ser., Am. Geophys. Un., Washington. D.C., 15, 245-251.

THAYER, D. (1974): An improved equation for the radio refractive index of air, Radio Sci., 9, 803-807.

Tregoning, P., R. Boers, D. O'BREIN and M. Hendy

(1998): Accuracy of absolute precipitable water vapor estimates from GPS observations, J. Geophys. Res., 103, 28,701-28,710.

Vedel, H., K.S. Mogensen and Y. Huang (2001):
Calculation of zenith delays from meteorological data comparison of NWP model, radiosonde and GPS delays, Phys. Chem. Earth (A), 26 (6-8), 497-582.

WMO (OMM) Organisation Meteorologique Mondiale (1975): Tables Meteorologique Internationales, n. 188, TP94.

(received March 4, 2002;

accepted October 10, 2002) 